\section{Determination of Cadmium, Chromium and Lead from Industrial Wastewater in Kombolcha Town, Ethiopia Using FAAS}

\section{Beshir Lega Muhammd*}

Department of Chemistry, Faculty of Natural and Computational Science, Debre Tabor University, Ethiopia

*Corresponding author: Muhammd BL, Department of Chemistry, Faculty of Natural and Computational Science, Debre Tabor University, Ethiopia, Tel: +251581416290; E-mail: legasbeshir@yahoo.com

Received date: May 08, 2018; Accepted date: June 09, 2018; Published date: June 14, 2018

Copyright: (C) 2018 Muhammd BL. This is an open-access article distributed under the terms of the Creative Commons Attribution License, which permits unrestricted use, distribution, and reproduction in any medium, provided the original author and source are credited.

\begin{abstract}
Industrial effluents discharged into the environment can cause a serious threat to agricultural products and health. In view of this, levels of some heavy metals, $\mathrm{Cd}, \mathrm{Cr}$ and $\mathrm{Pb}$ were determined in wastewater samples collected from BGI brewery, textile, and tannery industry in Kombolcha town using flame atomic absorption spectrometry. Based on the finding the average concentration at the point of discharge before treatment of their wastewaters for Cd is: $0.05 \pm$ $0.002,0.18 \pm 0.006,0.12 \pm 0.003$, for $\mathrm{Cr}$ is: $0.01 \pm 0.002,0.29 \pm 0.003,5.04 \pm 0.110$ and for $\mathrm{Pb}$ is: $0.15 \pm 0.012$, $1.97 \pm 0.026$ and $0.34 \pm 0.012$ respectively. On the other hand, the concentration at the point of discharge after treatment of their wastewaters for $\mathrm{Cd}$ is: $0.06 \pm 0.004,0.13 \pm 0.003,0.08 \pm 0.003$, for $\mathrm{Cr}$ is: $0.02 \pm 0.001,0.19 \pm$ $0.002,3.76 \pm 0.018$ and for $\mathrm{Pb}$ is: $0.11 \pm 0.007,1.53 \pm 0.008$ and $0.22 \pm 0.014$ respectively. The results obtained show that the mean values of all heavy metals in untreated wastewater samples (except Cd and Cr in BGI brewery) were significantly higher than the treated effluent $(P<0.05)$. These mean values have also exceeded the acceptable limits of EPA and WHO.
\end{abstract}

Keywords: BGI brewery industry; Environmental pollution; FAAS; Heavy metals; Tannery industry; Textile industry; Wastewater

\section{Introduction}

Industrialization plays a vital role in growth and development of any country. This rapid industrialization is also having direct and indirect adverse effects on environmental pollution [1]. Due to the side effect of industrialization on environments, environmental protection is the main need of the society to control generation of industrial wastewater that contain appreciable amount of metallic cation like zinc, copper, iron, lead, nickel, cadmium etc. Long term exposure of these effluents into the environment gives increased electrical conductivity, organic carbon content and heavy metals accumulation in the soil and a chance of their entrance in food chain which ultimately causes significantly health concern [2].

Industrial, agricultural and domestic activities have led to the pollution of the environment and increased the problems of waste disposal. The upsurge in urban population and the establishment of industries involved in the manufacture of various agrochemicals, petrochemical and household products have resulted to increase in the product of hazardous substances including heavy metals $[3,4]$.

Heavy metals enter the soil via beneficial agricultural additives such as lime, fertilizers, manure, herbicides, fungicides and irrigation waters as well as via potentially deleterious material such as sewage sludge, municipal composts, industrial and mine wastes, dredged materials and atmospheric deposits. Industrial wastes carrying heavy metals to the soils are adsorbed and retained by the organic and inorganic soil colloids. Plants absorb these metals from the soil in which some are essential for metabolic processes and other enzymatic reactions. The excessive uptake may cause phytotoxicity and consequently human toxicity as envisaged by the processes of bioaccumulation and biomagnifications [5].
It also enters the aquatic environment through atmospheric deposition, erosion of geological matrix or due to anthropogenic activities caused by industrial effluents, domestic sewage and mining wastes. The metal contaminants in aquatic systems usually remain either insoluble or suspension form and finally tend to settle down to the bottom are taken up by the organisms. Fishes being one of the main aquatic organisms in the food chain may often accumulate large amounts of certain metals [6].

According to recent investigation reported that elevated levels of heavy metals in vegetables are found from the area having long term uses of treated and untreated wastewater. Especially the determination of trace metal elements, particularly the heavy metals has received increasing attention in pollution studies. So, maximum efforts should be exercised to keep heavy metals especially $\mathrm{Cd}, \mathrm{Cr}, \mathrm{Ni}$ and $\mathrm{Pb}$ at the lowest rate in soils and plants $[3,4]$.

Heavy metal pollution has become one of the serious environmental problems of worldwide concern because of their extreme toxicity and tendency for bioaccumulation in the food chain even in relatively low concentrations. The toxic heavy metals cause serious threat to the environment, animals and humans because of their nonbiodegradable nature, long biological half lives and their potential to accumulate in different body parts. Excessive accumulation of heavy metals in agricultural soil through wastewater irrigation may not result in soil contaminations, but also affected food quality and safety. Some research confirmed that heavy metals such as cadmium, lead, copper, zinc and nickel have carcinogenic or toxic effect on human beings and environments [7].

Flame atomic absorption spectrometry (FAAS) is one of the most widespread traditional analytical techniques for trace element determination in different matrices [8]. It is a suitable technique for determining metals at part per million ( $\mathrm{ppm}$ ) concentration levels with good precision for many elements. FAAS offers air-acetylene and/or 
Page 2 of 5

nitrous oxide flame atomizer. Samples are introduced into the atomizer as an aerosol by the nebulizer. FAAS technique provides fast analysis of 10-15 s per sample, with very good precision (repeatability), moderate interferences that can be easily corrected, and relatively low cost [9].

Due to the rapid growth of industrialization, the environment specially the atmosphere and the water body or hydrosphere are largely exposed to pollution. Insufficient treatment or improper disposal of those wastes can vastly affect or even damage the living organism. Wastewater treatment is not given the necessary priority and therefore, industrial waste is discharged into receiving water bodies without treatment. As a result, proper management of wastewater is essential. To plan and implement the type and extent of its treatment, studying the kind and extent of toxicity of pollutants really prerequisite. For this reason, this study intends to determine the level of cadmium, chromium, and lead from industrial wastewater of BGI brewery, textile and tannery industry at Kombolcha town (Figure 1).

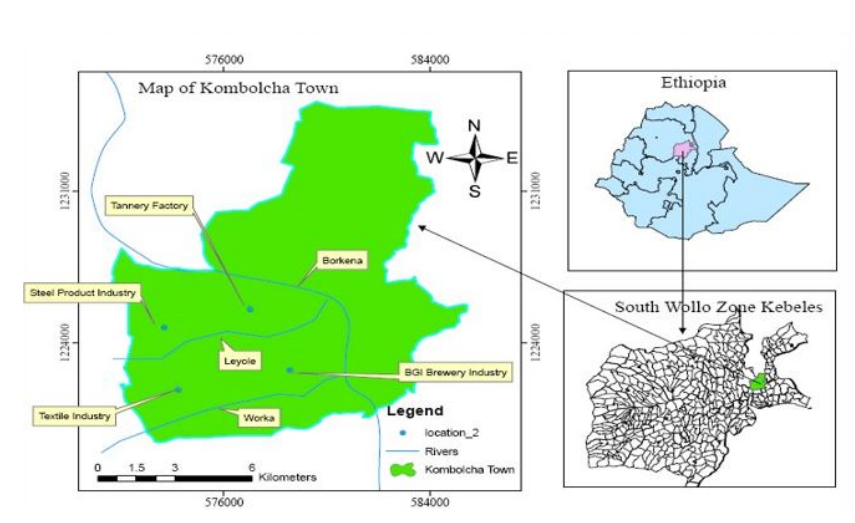

Figure 1: Map of the study area (Kombolcha).

\section{Materials and Methods}

\section{Material and instruments}

The instruments used in this experiment were; absorption spectrophotometer Model 210 Buck Scientific, Different size of volumetric flask, beakers, graduated cylinders, and pipette, watch glass, polyethylene plastic sample container, electronic balance, separatory funnel, filter paper, hot plate, ice containing box and refrigerator.

\section{Chemicals and reagents}

Concentrated nitric acid $\left(\mathrm{HNO}_{3}\right) 69 \%$ from Loba Chemie Pvt. Ltd., India, hydrochloric acid $(\mathrm{HCl}) 37 \%$ from $\mathrm{BDH}$ supplies poole, England, Lead nitrate $\left(\mathrm{Pb}\left(\mathrm{NO}_{3}\right)_{2}\right)$ from Blulux Laboratories Pvt. Ltd., $\mathrm{Cd}\left(\mathrm{NO}_{3}\right)_{2} \cdot 4 \mathrm{H}_{2} \mathrm{O}$ from Blulux Laboratories Pvt. Ltd., and $\mathrm{Cr}\left(\mathrm{NO}_{3}\right)_{3} \cdot 9 \mathrm{H}_{2} \mathrm{O}$ were used.

All polyethylene bottles and other working materials were thoroughly washed with detergent and rinsed with distilled water. Then they all soaked in $10 \% \mathrm{HNO}_{3}$ for about 12 hours. Finally, all of them were rinsed with distilled water and allowing them to dry before being used for either sampling or preparing standard solutions [10]. The wastewater samples were collected with $1 \mathrm{~L}$ capacity polyethylene bottles at the discharge point of industrial process just before and after the treatment of industrial effluents of BGI brewery, textile, and tannery at Kombolcha town. Before collecting the wastewater sample, the plastic bottles were washed carefully three times with sample. The sampling technique was systematic type because the sample is collected for $12 \mathrm{hr}$ within three hour $(3 \mathrm{hr}$ ) regular intervals of time and a composite type since the grab samples were collected and placed in the same bottle. However, each site of sample was kept in separate bottle with information written on it. Then the wastewater samples were transported to the laboratory by handling in ice containing box.

Before the sample was preserved, first the blank (distill water) consisting of metal free water was filtered to ensure freedom from contamination and then the sample was filtered using $0.45 \mu \mathrm{m}$ type whatman filter paper into a beaker and then the filtered sample was immediately preserved by acidifying it with concentrated nitric acid to $\mathrm{pH}<2$. The nitric acid used for this purpose was about $5 \mathrm{~mL} \mathrm{HNO}_{3}$ of $2.0 \mathrm{M}$ per $1 \mathrm{~L}$ sample. Finally, all samples were stored at $4^{\circ} \mathrm{C}$ in refrigerator to maintain the sample in a state that minimizes composition change or concentration of components in the time between collection and analysis [11]. $100 \mathrm{~mL}$ aliquots from a wellmixed acid preserved effluent sample were transferred to a $250 \mathrm{~mL}$ beaker. Then concentrated nitric acid $(10 \mathrm{~mL})$ and hydrochloric acid $(5$ $\mathrm{mL}$ ) was added to content of the beaker and heated on hot plate at $85^{\circ} \mathrm{C}$ under a hood until the volume of a content of a beaker was reduced to approximately $20 \mathrm{~mL}$. The beaker was covered with watch glass, refluxed for 30 minutes and subsequently allowed to cool and stand overnight to allow the precipitate to settle.

Thereafter, the clear supernatant was transferred to $50 \mathrm{~mL}$ volumetric flask, diluted to volume with distilled water, mixed thoroughly and stored in a sterile reagent bottle with glass stopper prior to analysis. In all cases, blanks were prepared using the same quantity of mixed acids [2].

In the use of FAAS for heavy metal analysis optimization of the operating conditions of the instrument is very crucial. Therefore, the analysis of $\mathrm{Cd}, \mathrm{Cr}$, and $\mathrm{Pb}$ began with selection and adjustments of various units of the FAAS (i.e., lamp selection, wave length selection, slit adjustment, energy and flame adjustment) as shown in Table 1.

\begin{tabular}{|l|l|l|l|l|l|}
\hline No. & Parameter & unit & For Cd & For $\mathbf{C r}$ & For $\mathbf{P b}$ \\
\hline 1 & Wave length & $\mathrm{nm}$ & 228.9 & 357.9 & 283.3 \\
\hline 2 & Current & $\mathrm{mA}$ & 2.0 & 2.0 & 2.0 \\
\hline 3 & Slit width & $\mathrm{nm}$ & 0.7 & 0.7 & 0.7 \\
\hline 4 & Energy & $\mathrm{eV}$ & 2.884 & 3.7 & 2.805 \\
\hline 5 & Fuel & - & acetylene & acetylene & acetylene \\
\hline 6 & Oxidant & - & air & air & air \\
\hline
\end{tabular}

Table 1: Instrumental operating conditions for determination of heavy metals in wastewater samples using FAAS [12].

FAAS was standardized by aspirating distilled water to get zero absorbance. Stock solutions of $1000 \mathrm{mgL}^{-1}$ for all the metals was prepared. Then the working solutions were prepared by serial dilution. After serial dilution, the working solution was taken to FAAS and the absorbance value was measured. The concentration (in $\mathrm{mgL}^{-1}$ ) was obtained by using values of absorbance and linear regression equation of the calibration curve of these heavy metals. The procedure was repeated three times for all the samples [13]. 


\section{Results and Discussion}

In this study the concentration of heavy metals was determined from industrial wastewater of Kombolcha BGI brewery, tannery and textile industry using FAAS. A series of working standard solutions were prepared from $100 \mathrm{mg} / \mathrm{L}$ intermediate standard solutions of their respective metals and the solutions were aspirated into the atomizer. The calibration graphs and correlation coefficients of each of the heavy metals were determined by plotting the absorbance of the working standards versus their corresponding concentration.

In this study the trend occurrence of the heavy metals concentration in untreated and treated wastewater samples of BGI brewery were the order of $\mathrm{Pb}>\mathrm{Cd}>\mathrm{Cr}$. Therefore, the value obtained from this site calculated at the $95 \%$ confidence level can be compared directly by the following bar graph. As shown in Figure 2 the concentration of lead before treatment of BGI effluent is higher than Cd and Cr. While Cd and $\mathrm{Cr}$ were found higher concentration in treated effluent than untreated effluent in BGI brewery wastewater sample. This because that there is some addition of effluents from other sources in the treatment plant. Such as laboratory waste and toilet room effluent contributed the high level of $\mathrm{Cd}$ and $\mathrm{Cr}$ in treated effluent than untreated.

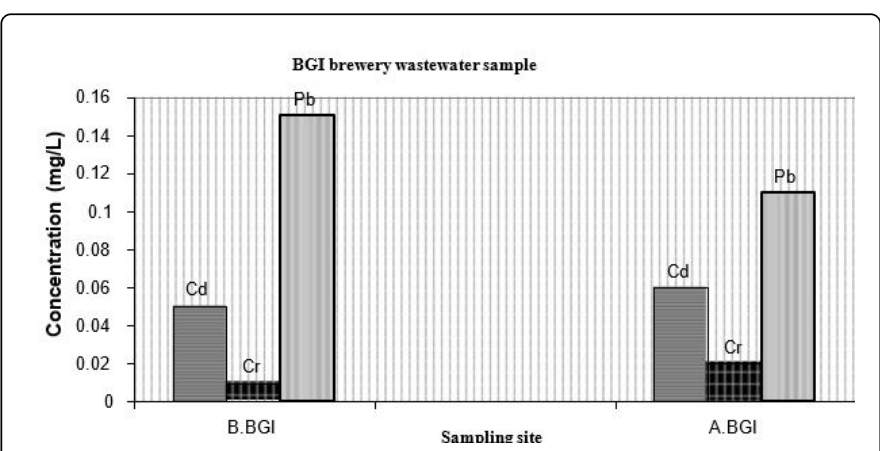

Figure 2: Comparison of the level of $\mathrm{Cd}, \mathrm{Cr}$ and $\mathrm{Pb}$ before and after treatment of BGI brewery industrial wastewater sample.

As shown in Figure 3, the trend occurrence of heavy metals concentration in untreated and treated wastewater sample of textile industry was in the order of $\mathrm{Pb}>\mathrm{Cr}>\mathrm{Cd}$ whereas, the trend occurrence of heavy metals concentration in untreated and treated wastewater sample of tannery industry was in the order of $\mathrm{Cr}>\mathrm{Pb}>\mathrm{Cd}$ as shown in Figure 4 . Therefore, the value obtained from this site calculated at the 95\% confidence level can be compared directly by the following bar graph. The mean concentrations of heavy metals in untreated textile and tannery industrial wastewater were higher than treated. This due to the fact various chemicals are used in tanning, soaking, dying process for the production of hides, skins and textile.

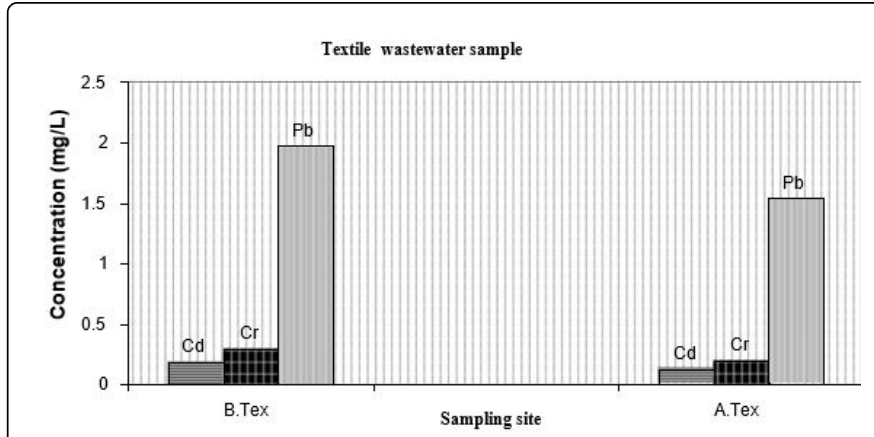

Figure 3: Comparison of the level of $\mathrm{Cd}, \mathrm{Cr}$, and $\mathrm{Pb}$ before and after treatment of textile industrial wastewater sample.

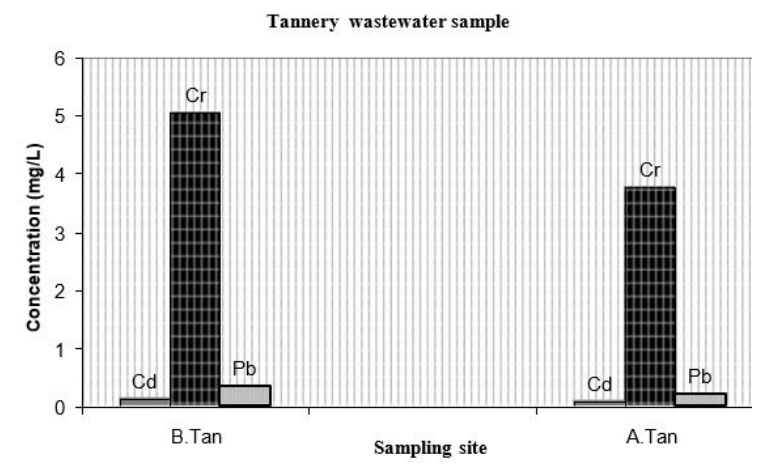

Figure 4: Comparison of the level of $\mathrm{Cd}, \mathrm{Cr}$, and $\mathrm{Pb}$ before and after treatment of tannery industrial wastewater sample.

In this study the analytical results revealed that the average concentration of chromium in effluents of BGI brewery, textile, and tannery industries were $(0.019-0.021,0.188-0.192,3.742-3.778) \mathrm{mg} / \mathrm{L}$, respectively [14]. As shown in the table the chromium metal in tannery and textile effluents were lower than Deepali and Gangwar values for tannery and textile industries effluents in Indian respectively and higher than Nasrullah et al. [1] values for textile industry effluent in Pakistanian, but within the range Ogunlaja and Aemere [15] results for textile industry effluent of Nigerian. This high level of $\mathrm{Cr}$ in Indian industrial effluent may be due to the continuous disposal of untreated industrial effluents and the reagent used in tanning and dye process.

In the present study the cadmium content of textile industry effluent was $0.127-0.133 \mathrm{mg} / \mathrm{L}$, which is higher than that Deepali and Gangwar values [14] of Indian and Nasrullah et al. [1] values of Pakistanian but within the range of Ogunlaja and Aemere [15] results of Nigeria textile industry effluent. In the case of BGI brewery industry, the content of Cd was higher than that of Nasrullah et al. [1] values of Pakistan brewery industry effluent. Thefore, the discharge of industrial effluent to Borkena river which is used as a domestic purpose leads to a buildup of cadmium in the kidneys and possible kidney disease. Other potential long-term effects are lung damage and fragile bones.

The value of lead was $1.522-1.538 \mathrm{mg} / \mathrm{L}$ in textile effluent of this study, while lower value of was observed in the effluent of Nasrullah et al. [1] values of textile industry in Pakistan. It is also shown in previous study of Ethiopia (Kombolcha), the content of $\mathrm{Pb}$ was $0.134 \mathrm{mg} / \mathrm{L}$ reported by Mengesha [16]. 
This finding implies that the discharge of these heavy metals into water bodies can cause water pollution. Consumption of the polluted water by animals or human beings could be hazardous to their health. Soil contaminated by these effluents will produce unhealthy food as heavy metals can enter the food chain and thus be consumed by human beings. For instance, the mean values of $\mathrm{Pb}$ from the polluted areas, which was found to be above the maximum permissible level, could exert toxic effects on human beings if consumed from the water or irrigated agricultural products from the sites.

The presence of a wide range of components in the effluents from BGI brewery, textile and tannery industries in Kombolcha underscore the need to further process the effluents prior to discharge into receiving waters. The effluents are directly discharged into Worka river that enters into Borkena river. As Mengesha [16] reported that the Borkena river acts as a source of water supply for domestic use of inhabitants of localities. This loss of water quality is causing health hazards and death of human, livestock and death of aquatic lives, crop failure and loss of aesthetics.

When the result of the heavy metal concentrations was compared with other country standards, the concentration of cadmium, chromium and lead at BGI brewery, textile, and tannery wastewaters which were in average range of (0.056-0.083, 0.019-0.192, $0.1030-0.234) \mathrm{mg} / \mathrm{L}$ respectively found within the limit of national environmental quality standard for liquid industrial effluents of Pakistan except $\mathrm{Cd}$ and $\mathrm{Pb}$ in textile and $\mathrm{Cr}$ in tannery. However, the average concentration range of these metals exceeded the acceptable limits of EPA of Nigeria and WHO value of Indian $[1,15]$.

Generally according to Figures 2-4 the treatment process doesn't work effectively for metal concentration reduction. So those industries use other methods for treating industrial wastewater containing heavy metals often involve technologies for reduction of toxicity in order to meet technology-based treatment standards. Among those heavy metal removals method, bio adsorption is a new biological method and various low-cost bio adsorbents (agricultural waste, forest waste, industrial waste, algae etc.) are used for maximum removal of heavy metals from wastewater. Bio adsorption techniques are ecofriendly best solutions for removing heavy metals from wastewater rather than physicochemical methods [17].

\section{Conclusion}

In this study, heavy metals such as $\mathrm{Pb}, \mathrm{Cr}$ and $\mathrm{Cd}$ have been determined via FAAS. The concentration of chromium was higher than cadmium and lead in treated and untreated wastewater of tannery industry. In BGI brewery, however, the level of cadmium and chromium were higher after treatment than before treatment. This might be due to the internal corrosion of wastewater pipe that has been used. In the case of textile industry concentration of lead was higher than chromium and cadmium both in untreated and treated. The concentrations of trace heavy metals in treated effluent have exceeded the recommended values of EPA of Nigerian and WHO. However, from the overall aspects of the study, the treated effluent was considered unsuitable and cannot be used as an alternate means of irrigation purpose.

\section{Recommendation}

The Researcher recommends the following:
(1) Treatment of heavy metals in industrially released wastewater is important to keep good environmental health, human and aquatic life. Unfortunately, the BGI Brewery industry of Kombolcha, Ethiopia does not have efficient treatment plant that treat heavy metals of wastewater discharge. So it is expected to create awareness for an administrator of the BGI Brewery industry to use another treatment plant that treat the discharge of heavy metals.

(2) To all industry there could be "direct reuse of wastewater and adsorption of these heavy metals from aqueous solution by wheat straw in combination." Because:

(a) The wastewater in pretreatment site is potentially rich with these metals; hence direct use of it is cost effective.

(b) These heavy metals are higher in concentration or even beyond the limit in after treatment site for all industry. It needs to be avoided from effluent. This could be done by constructing one tank next to final tank filled with sand and allowing the effluent to pass through after filling with wheat straw.

(3) The environmental agencies or other responsible bodies should control this by testing such discharges starting from its point source up to the way that can be diminished at maximum from time to time.

(4) Eventually the researcher believes that this study is not complete and finalized. But, it can be taken as an initiative or can be used as a base for further investigation of environmental pollution.

\section{References}

1. Naz NR, Bibi H, Iqbal M, Durrani M (2006) Pollution load in industrial effluent and ground water of Gadoon Amazai Industrial Estate (GAIE) SwabI, NWFP. J Agricultural Biological Science 1: 18-24.

2. Singh V, Chandel CPS (2006) Analytical study of heavy metals of industrial effluents at Jaipur, Rajasthan (India). J Environ Science Engineering 48: 103-108.

3. Oguzie FA, Okhagbuzo GA (2010) Concentrations of heavy metals in effluent discharges downstream of Ikpoba river in Benin City, Nigeria. African J Biotechnology 9: 319-325.

4. Chalapathi K, Ravi V, Maddaiah GP (2010) Determination of Cr(III), $\mathrm{Cu}(\mathrm{II}), \mathrm{Zn}(\mathrm{II}), \mathrm{Cd}(\mathrm{II})$ and $\mathrm{Pb}(\mathrm{II})$ in food samples by FAAS after preconcentration on silica gel modified with 5-[2hydroxybenzylideneamino]-2-hydroxy benzoic acid. J Chem Pharm Res 2: 452-461.

5. Midrar-ul-haq M, Puno HK, Khattak RA, Saif MS (2003) Contamination of the agricultural Land due to industrial activities in Karachi (Sindh). Int J Agri Biol 5: 150-153.

6. Ghasem M, Rahimnejad M, Najafpour GD, Sedighi M, Asadi M, et al (2008) Investigation on batch biosorption of lead using Lactobacillius bulgaricus in an aqueous phase system. Int J Published by the Nigerian Society for Experimental Biology 20: 41-46.

7. Islam MM, Halim MA, Safiullah S, WaliluHaque SAM, Islam MS (2009) Heavy metal $(\mathrm{Pb}, \mathrm{Cd}, \mathrm{Cu}, \mathrm{Cr}, \mathrm{Fe}$, and $\mathrm{Mn})$ content in textile sludge in Gazipur, Bangladesh. Research J Environ Science 3: 311-315.

8. Lagalante AF (1999) Atomic absorption spectroscopy: A tutorial review. Appl Spectrosc Rev 34: 173-189.

9. Helaluddin ABM, Khalid RS, Alaama M, Abbas SA (2016) Main Analytical Techniques Used for Elemental Analysis in Various Matrices. Trop J Pharm Res 15: 427-434.

10. Ajanaku K, Taiwo A (2011) Heavy metal analysis of industrial discharges in Lagos, Nigeria. Terrestrial and Aquatic Environmental Toxicology 5: 77-79.

11. Seda $\mathrm{T}$ (2007) Determination of common ions and heavy metals in bottled mineral water consumed in Addis Ababa (Ethiopia). 
Citation: Muhammd BL (2018) Determination of Cadmium, Chromium and Lead from Industrial Wastewater in Kombolcha Town, Ethiopia Using FAAS. J Environ Anal Chem 5: 243. doi:10.4172/2380-2391.1000243

Page 5 of 5

12. Buck Scientific (2005) 210/211VGP, Atomic Absorption Spectrometer Operation Manual.

13. Deepali K, Gangwar K (2010) Metals concentration in textile and tannery effluents, associated soils and ground water. New York Science J 3: 82-89.

14. Ogunlaja OO, Aemere O (2009) Evaluating the efficiency of a textile wastewater treatment plant located in Oshodi, Lagos. African Journal of Pure and Applied Chemistry 3: 189-196.

15. Mengesha $\mathrm{A}$ (2010) Voltametric study of pollution potential of $\mathrm{Pb}$ and $\mathrm{Cd}$ in Borkena river water and industrial effluents at Kombolcha.
16. Singh A, Sharma RK, Agrawal M, Marshall FM (2010) Risk assessment of heavy metal toxicity through contaminated vegetables from waste water irrigated area of Varanasi, India. Tropical Ecology 51: 375-387.

17. Gunatilake SK (2015) Methods of Removing Heavy Metals from Industrial Wastewater. Journal of Multidisciplinary Engineering Science Studies 1: 12-18. 